\title{
O papel que aprisiona
}

The trap in the paper

\section{Juliana Prestes de Oliveira}

Universidade Federal de Santa Maria - UFSM - Santa Maria - Rio Grande do Sul - Brasil

\author{
Nícollas Cayann Teixeira Dutra
}

Universidade Federal de Santa Maria - UFSM - Santa Maria - Rio Grande do Sul - Brasil

\section{Amanda L. Jacobsen de Oliveira}

Universidade Federal de Santa Maria - UFSM - Santa Maria - Rio Grande do Sul - Brasil

Resumo: Este trabalho busca refletir acerca dos significados presentes no conto "O papel de parede amarelo", de Charlotte Perkins Gilman (2017), publicado em 1892. Intenta-se, também, entender como são discutidos, no texto, os aprisionamentos das mulheres a papéis sociais. Por meio de uma narrativa em primeira pessoa, no conto é possível conhecer a história de uma personagem mulher que foi forçada ao confinamento por seu marido e médico, John. A escolha do marido em fazer isso se dá com a intenção de curá-la de uma depressão nervosa e, assim, a proíbe de fazer qualquer esforço físico ou mental. Por meio da teoria de Laqueur (2001) sobre a invenção do sexo, compreende-se que o discurso científico é apresentado no texto como uma ferramenta de poder, pelo qual mulheres eram mantidas presas aos papéis sociais de esposa e mãe. A teoria de Luce Irigaray (1992) auxilia no entendimento sobre a linguagem como meio de manutenção do patriarcado, por isso a dificuldade da protagonista em libertar-se com auxílio da escrita sobre si. Ao ficar aprisionada em um quarto decorado com um horroroso papel de parede amarelo, a protagonista fica obcecada pela estampa do mesmo, discorrendo sobre ele e seus padrões. Tal narrativa permite traçar paralelos com as situações vivenciadas por ela, enquanto mulher e esposa, e por várias mulheres, em nossa sociedade. Além disso, nela é possível perceber a imposição de papéis sociais como uma das práticas usadas pelo patriarcalismo para subjugar e determinar o comportamento feminino.

Palavras-chave: Papel de parede amarelo. Mulheres. Aprisionamento. Charlotte Gilman.

Abstract: This work discusses the meanings in Charlotte Perkins Gilman's short story, "The yellow wallpaper" (2017). We look to the way in which the text discusses women imprisonment to social roles. Through a first-person narrative the short story tells us the story of a female character forced to confinement by her husband and doctor, John. In doing so, the husband has the intention of healing her of a nervous depression and, thus, he forbids her to do any physical and mental effort. By Laqueur's theory about the invention of sex (2001) we understand that the scientific discourse is presented in the text as power instrument by which women were kept trapped to the social roles of wife and mother. Luce Irigaray's theory (1992) helps us to understand language as instrument and means of maintaining patriarchy, therefore the protagonist's struggle in breaking free boosted by self-writing. While trapped in a bedroom adorned with a horrific yellow wallpaper the protagonist becomes obsessed by its pattern, writing obsessively about it. This narrative allows us to draw parallels with her circumstances whereas woman and wife, as well as the circumstances of women in our society. Besides that, in this woman we can notice the imposition of social roles as one of the practices used by patriarchalism to overpower and to determine women's behavior.

Keywords: The yellow wallpaper. Women. Imprisonment. Charlotte Gilman. 
"Ao contrário de José, seu marido, Maria não é piedosa nem justa, porém não é sua culpa dessas mazelas morais, a culpa é da língua que fala, senão dos homens que a inventaram, pois nela as palavras justo e piedoso, simplesmente, não têm feminino" (SARAMAGO, 2005, p. 22).

"E convém observar que houve uma falha na formação da primeira mulher, por ter sido ela criada a partir de uma costela recurva, ou seja, uma costela do peito, cuja curvatura é, por assim dizer, contrária à retidão do homem. E como, em virtude dessa falha, a mulher é animal imperfeito, sempre decepciona e mente" (KRAMER; SPRENGER, 2016, p. 124).

\section{Introdução}

A Bíblia descreve a criação da mulher como parte integral do homem: "E da costela que o SENHOR Deus tomou do homem formou uma mulher; e trouxea a Adão. E disse Adão: Esta é agora osso dos meus ossos e carne da minha carne" (Gn 2: 21-25). Durante muito tempo acreditou-se que as mulheres eram do mesmo corpo que o homem. Somente em 1759 o esqueleto masculino foi comparado ao primeiro desenho de um esqueleto feminino, ilustrando as diferenças básicas entre os dois corpos (LAQUEUR, 2001, p. 22). O modelo narrativo responsável pelo estabelecimento do corpo da mulher em condições de subjacência ao corpo masculino é constantemente perpetuado por premissas essencialmente sexistas. Dessa forma, a mulher é vista como algo pertencente ao homem, como se dele ela dependesse para existir. O vínculo de posse fica então estabelecido na dicotomia homem vs. mulher: mulheres são objetos/bens e homens são proprietários.

A mulher como propriedade do marido, do pai, ou de qualquer homem, ou até mesmo de seres míticos, bíblicos e afins, trata-se de uma subordinação que persegue e aprisiona as mulheres historicamente, ampliando, assim, questões de violência doméstica, por exemplo. Como Irigaray (1992) evoca em sua obra, a linguagem é um meio de dominação masculina, uma ferramenta que auxilia na manutenção do patriarcado. Ademais, é na consciência do homem, mais do que nas instituições por ele criadas, que o aprisionamento dos corpos, principalmente o feminino, acontece. Conforme Kate Millett, em Política sexual (1970, p. 12), a "[...] sociedade patriarcal está de tal forma enraizada que o tipo de estrutura que ela determina em ambos os sexos é talvez mais um hábito de espírito e um tipo de vida do que um sistema político determinado"

A fim de discutir tais questões, neste artigo, realizamos a leitura do conto O papel de parede amarelo (2017), de Charlotte Perkins Gilman, buscando entender alguns dos papéis sociais que aprisionam as mulheres há tantos anos. Gilman escreve uma narrativa em primeira pessoa, apresentando a personagem mulher, protagonista do enredo, que foi forçada ao confinamento por seu marido e médico, John. Tal isolamento, segundo o marido, é com a intenção de curá-la de uma depressão nervosa e, assim, a proíbe de fazer qualquer esforço físico ou mental. Para pensar esse fato, usamos a teoria de Laqueur (2001) sobre a invenção do sexo, na qual compreende-se que o discurso científico é usado como uma ferramenta de poder, que mantém as mulheres presas aos papéis sociais de esposa e mãe. Além disso, partimos da teoria de Luce Irigaray (1992) para entender sobre a linguagem como meio de manutenção do patriarcado, por isso a dificuldade da protagonista em libertar-se com auxílio da escrita sobre si. Tal narrativa permite traçar paralelos com as situações vivenciadas pela personagem, enquanto mulher e esposa, e por várias mulheres, em nossa sociedade. Além disso, nela é possível perceber a imposição de papéis sociais como uma das práticas usadas pelo patriarcalismo para subjugar e determinar o comportamento feminino.

\section{The trap in the (yellow wall) paper}

Ao lermos os quatro primeiros parágrafos do conto $O$ papel de parede amarelo (publicado originalmente como um conto, sendo no Brasil publicado como um livro), de Charlotte Perkins Gilman, somos facilmente induzidos a pensar em uma história que envolve o sobrenatural. Entretanto, tal ideia começa a desmoronar quando a narradora/protagonista narra a reação do marido diante das crenças dela: "John ri de mim, é claro, mas isso é de se esperar no casamento" (GILMAN, 2017, p. 12). Passamos então a desconfiar do que será narrado. Nas próximas páginas talvez nos 
depararemos com um casamento onde há o opressor (homem) e a oprimida (mulher), e não um enredo que evoca o misticismo.

A história, publicada pela primeira vez em 1892, é narrada em primeira pessoa por uma mulher forçada ao confinamento por John, seu marido e médico, com a intenção de curá-la de uma depressão nervosa; e ele o faz com base em seus conhecimentos científicos, usando sua posição de poder para proibi-la de fazer qualquer esforço físico e mental. Ele a mantém longe do filho, fechada em um quarto decorado com um horroroso papel de parede amarelo. O vivido pela protagonista pode ser aproximado daquilo que Millett (1970) evoca como a morte da mulher ao se casar, uma morte que não é somente aos olhos da lei, em semelhante aos criminosos que perdem todos os seus direitos, mas uma morte da sua identidade. A mulher passa a observar e discorrer incessantemente sobre o papel de parede e seus padrões, tornando-se obcecada. Por meio dessa narração, podemos traçar paralelos com as situações vivenciadas por ela, enquanto mulher e esposa, e por várias outras mulheres.

O casal está de passagem em uma mansão colonial, onde a protagonista deveria, de acordo com o marido, "descansar", tratando-se de uma necessidade para que a mulher se cure de suas supostas condições debilitadas e frágeis. O que mais prende a atenção nas descrições do local é a utilização do vocábulo "colonial", que faz referência à condição de subordinação na qual a protagonista estará presa nos contornos das relações que vivencia no decorrer das páginas do conto. Além da imagem colonial atrelada a esse casamento e situação da mulher, a narrativa nos leva a pensar como o matrimônio é uma espécie de feudalismo, que escravizava e explorava a mulher, algo que para Millett fica evidente na cerimônia matrimonial, "[...] quando a mulher e o homem se tornam 'um só', esse 'um' era o homem (MILLETT, 1970 , p. 18, grifos da autora).

No início do enredo também nos deparamos com uma das práticas usadas pelo patriarcado para subjugar e determinar o comportamento, os direitos e o "papel" da mulher: o discurso de autoridade, principalmente aquele baseado na ciência:

John é prático ao extremo. Não tem paciência para questões de fé, nutre um imenso horror à superstição e zomba abertamente de qualquer conversa sobre coisas que não podem ser vistas nem sentidas nem traduzidas em números.

John é médico, e talvez - (eu não o diria a vivalma, é claro, mas segredar apenas ao papel já é um grande alívio para minha mente) -, talvez por isso que não me recupero mais rápido.

O fato é que ele não acredita que estou doente!

E o que se pode fazer?

Se um médico de renome, que vem a ser seu próprio marido, assegura aos amigos e parentes que não se passa nada grave, que se trata apenas de uma depressão nervosa passageira - uma ligeira propensão à histeria -, o que se pode fazer?

Meu irmão também é médico, e também de renome, e diz o mesmo.

Assim, tomo fosfatos ou fosfitos - não sei ao certo -, e tônicos e ar fresco e dou caminhadas e faço exercícios e estou absolutamente proibida de "trabalhar" até me restabelecer (GILMAN, 2017, p. 12-13, grifos da autora).

Mostra-se uma desvalorização da fala da protagonista, bem como daquilo que está, culturalmente, atrelado à mulher. Muitas vezes, essas "crenças femininas" são utilizadas pelo poder patriarcal para estigmatizar as mulheres e rotulá-las como loucas, histéricas ou bruxas. Assim como muitas mulheres do século XIX foram adoecidas ou enlouquecidas, a protagonista é colocada nessa posição de "doente" por um homem, seu próprio marido. O diagnóstico dado e os métodos de tratamento escolhidos ambos pelo marido-médico (em concordância do irmão-médico) - para a possível patologia relacionada ao suposto estresse que preocupa e desestabiliza a personagem - são feitos sem considerar a opinião da esposa/paciente sobre si mesma. Seu posicionamento médico faz do discurso de John sensato e correto, exímio de questionamentos: "sei do que estou falando, querida, sou médico" (GILMAN, 2017, p. 40).

Como Thomas Laqueur traz em seu livro Inventando o sexo: corpo e gênero dos gregos a Freud (2001), por muitos séculos, o científico, a medicina, as 
descobertas e as teorias sobre o corpo e mente humana eram realizadas apenas por homens; e por isso os documentos médicos, jurídicos e literários retratavam o modo operante da hierarquia do masculino. Foram homens que pesquisaram e cunharam ideias sobre o feminino, sempre tratando-o como algo defeituoso e inferior ao masculino, a mente feminina como propensa a delírios e histerias. Tudo isso legitimava (e ainda o faz) posicionamentos machistas e a segregação das mulheres. Acreditavase (ou acredita-se ainda hoje?), haver um sexo (masculino) mais perfeito e merecedor de privilégios do que o outro (feminino), inferior e subalterno.

A subjetividade da protagonista é adoecida. Ao pensar sobre o modo como é tratada, ela nos revela: "Em particular, discordo da opinião deles. Em particular, acredito que um trabalho adequado, com estímulos e variedade, iria me fazer bem. Mas o que fazer?" (GILMAN, 2017, p. 13). Contudo, o conhecimento dela sobre si mesma não é considerado pelo marido-médico, pois a voz feminina não tinha espaço para a construção de saber, nem mesmo quando se tratava de algo que ela vivencia ou sente. $O$ conhecimento sobre o corpo e a mente da mulher foi construído por homens, devido a não permissão da presença de mulheres no campo da ciência. Como Kate Millett aponta, ao discutir as teorias e estudos freudianos em relação à mulher,

Qualquer desejo de uma existência
menos humilhante e menos confinada é
imediatamente atribuído a um desvio
anormal e irrealista em relação à sua
identidade genética e por consequência
ao seu destino. A mulher que resiste à
«feminidade», isto é, que recusa o
temperamento, o estatuto e a função
femininos, passa por expor-se à
neurose, porque a feminidade é a sua
sina como «a anatomia é o destino». Ao
tentar escapar assim ao único destino
que a natureza lhe reserva, ela caminha
para o nada (MILLETT, 1970, p. 191-
192, grifos da autora).

A narradora-personagem permanece encarcerada em um quarto que the desagrada, decorado com um papel de parede que contribui para sua inquietação. É proibido o contato com parentes, amigos, e até mesmo com seu filho, Ihe é severamente vetado qualquer esforço ou trabalho, ao ponto que a única salvação possível à protagonista é o ato de escrever. Manter os diários permite que a psique da protagonista se mantenha com alguma sanidade. Assim como Betty Friedan, em Mística feminina (1971), afirma que as mulheres americanas de sua época eram inteligentes e habilidosas, mas estavam vivendo uma vida que lhes negava o pleno uso de suas faculdades, é possível afirmar que a protagonista deste conto também tem sua inteligência e capacidades sufocadas pelo casamento.

O direito de escrever livremente lhe é tolhido, ela passa a escrever escondida. A perda da escrita é, metaforicamente, combinada à perda das faculdades psíquicas e mentais da saúde da personagem. Diante do conto nos vemos lendo o diário da narradoraprotagonista. $O$ fato de ser uma escrita da protagonista e, desse modo, a voz predominante ser dela, corrobora a ideia de haver um embate entre a perspectiva dela e a do marido sobre a sua condição. Há então, dois discursos de saberes bem distintos: o da ciência, sustentado pelo marido, e da escrita confessional, proferido pela protagonista. Segundo Laqueur (2001), o saber considerado pela sociedade como verdadeiro é o científico (produzido por homens), por isso a desconsideração de John acerca das vontades, ideias e sensações de sua esposa. A protagonista fica à mercê do esposo e do que ele lhe impõe. John é médico, o patriarca da casa e o soberano no casamento, conforme o costume vigente na sociedade, restando a ela o papel de mulher submissa. É possível perceber ainda a exaustão da esposa por ter de fingir para o marido e para a cunhada ser alguém que não é. Escrever também é, para ela, algo cansativo, prática realizada com menos frequência desde que chegou na casa de campo. $O$ motivo disso não é explícito, mas pode ser entendido da seguinte forma: escrever sobre si e sua condição a deixa inquieta e deprimida. Isso ocorre devido ao seu entendimento sobre os fingimentos que vive, a situação de submissão e a impotência diante dos atos e decisões do marido. Ao escrever, ela percebe que está sozinha. Durante a escrita, ela tenta um exercício de linguagem e escreve com dor, pois percebe a incapacidade de ação para mudar tal situação: 
Não sei por que escrevo isto.

Não é algo que eu queira fazer.

Não me sinto capaz.

E sei que John acharia um absurdo.

Mas tenho que expressar de alguma

forma o que sinto e penso - é um alívio tão grande!

O esforço, contudo, está se tornando maior do que o alívio (GILMAN, 2017, p. 35).

Para manter seu poder sobre a esposa, John busca silenciá-la de todas as formas, utilizando-se da autoridade do discurso médico:

Fico sempre imaginando pessoas a caminhar por todos esses caramanchões e alamedas, mas John me advertiu a não me entregar a tais devaneios. Ele me disse que, com o poder de imaginação que tenho e meu hábito de inventar histórias, uma debilidade dos nervos como a minha só pode resultar em fantasias exaltadas, e que devo usar minha força de vontade e meu bom senso para controlar essa propensão. É o que tento fazer.

Às vezes tenho a impressão de que, se ao menos me sentisse bem o suficiente para escrever um pouco, isso aliviaria minha confusão de ideias e me traria algum descanso.

Mas, sempre que tento, acabo ficando bastante cansada (GILMAN, 2017, p. 23 - grifo nosso)

A escrita da protagonista revela a sua subjetividade. No entanto, assim como discutido por Luce Irigaray (1992), a linguagem é predominantemente masculina, e um dos meios de manutenção do patriarcado. Isso prejudica a mulher na tentativa de expressar-se e revelar seus anseios, desejos e pensamentos: "o sexo é uma importante dimensão cultural, mas necessitamos encontrar um novo equilíbrio para as relações entre os sexos e a língua, a sociedade e a cultura" (IRIGARAY, 1992, p. 31, tradução nossa).

Ao pensar sobre o discurso científico do marido médico e o discurso confessional da protagonista podemos refletir acerca do modo como a diferença sexual está vinculada à cultura e à linguagem, e como os valores considerados universais manifestam-se como domínio de uma parte da humanidade (homens) sobre a outra (mulheres). Tal dominação está tão presente como algo natural que os próprios dominados acabam ficando uns contra os outros, reforçando a submissão. Se pensarmos na condição das mulheres desta narrativa (a protagonista e sua cunhada), entendemos o quanto as mulheres desconhecem a si mesmas e às suas subjetividades, e como nossa cultura está organizada de forma a separar as mulheres. A cunhada corrobora para o aprisionamento e adoecimento da protagonista:

Lá vem a irmã de John. Ela é tão querida, tão atenciosa comigo. Não posso permitir que me veja escrevendo. Ela é uma dona de casa primorosa e entusiasmada e não aspira a uma ocupação melhor. Não tenho dúvidas de que ela pensa que foi a escrita que me deixou doente! (GILMAN 2017, p. 26).

Não há entre elas qualquer cumplicidade, e o resultado é o não conhecimento das mulheres sobre quem são; não há genealogias femininas, as mulheres não constroem histórias e memórias sobre si mesmas; o que temos são perspectivas masculinas e uma linguagem masculina, tidas como universais, que corroboram com a submissão e apagamento feminino. A compreensão da condição de aprisionamento da protagonista é perceptível não somente pela narrativa direta sobre isso, mas pelas metáforas e ironias presentes ao longo do texto. Talvez por considerar exaustivo escrever sobre si diretamente, e porque pensar na sua condição a faz sentir-se mal, ela decide: "Então vou deixar essa questão de lado e falar sobre a casa" (GILMAN, 2017, p. 14); descrevendo principalmente o recinto no qual está:

Trata-se de um quarto amplo arejado que ocupa quase todo o andar, com janelas por toda a volta e abundância de ar e luz. Creio que a princípio foi um quarto infantil, depois sala de brinquedos e ginásio, pois as janelas são gradeadas e há argolas e coisas do tipo nas paredes.

A tinta e o papel de parede dão a impressão de que funcionou aqui uma escola para meninos. Grandes pedaços de papel foram arrancados acima da cama, até onde consigo alcançar, e também do outro lado do quarto, perto do chão. Nunca vi na vida um papel tão feio. 
Um desses padrões irregulares e exagerados que cometem todo tipo de pecado artístico.

É esmaecido o bastante para confundir o olho que o segue, intenso o bastante para o tempo todo irritar e incitar seu exame, e, quando seguimos por um tempo suas curvas imperfeitas e duvidosas, elas de súbito cometem suicídio - afundam-se e ângulos deploráveis, aniquilam-se em contradições inconcebíveis.

A cor é repulsiva, quase revoltante; um amarelo enfumaçado sujo, estranhamente desbotado pela luz do sol, em seu lento transladar.

Em alguns pontos, é de um alaranjado pálido e desagradável; e outros, de um tom sulfuroso e enjoativo.

Não me espanta que as crianças o odiassem! Eu mesma o odiaria se tivesse de viver muito tempo neste quarto (GILMAN, 2017, p. 16-18).

O quarto pode ser lido como um local de aprisionamento, devido às grades e de certa dominação e padronização de pensamentos, costumes e comportamentos. Se considerarmos que se tratava de uma escola para meninos, onde, na época, nas salas de aulas, dominava o ensino de disciplina, do bom comportamento e da obediência, a compreensão do enclausuramento vivido pela protagonista, tanto ao ficar trancada no quarto, quanto a ser obrigada a agir de acordo com a moral e costumes da época. A ideia de ter sido um quarto infantil, assim como o de escola, pode ser uma representação da situação de pertencimento a alguém, geralmente ao homem, e de submissão da mulher, que começa desde criança, e das próprias crianças em si. Tal pensamento nos leva a pensar na discussão proposta por Firestone (1976) sobre a família biológica, na qual ocorre "[...] um poder de distribuição inerentemente desigual" (FIRESTONE, 1976, p. 18), onde o homem domina tanto a mulher quanto os filhos. Desde crianças os sujeitos são criados dentro de uma estrutura de submissão nas relações existentes entre os sexos e hierarquias familiares. A aproximação entre a infância e a mulher casada pode ser um modo de trazer à discussão a segregação, o desrespeito e a opressão a que crianças e mulheres estão submetidas. Bem como o papel de parede amarelo pode ser lido como a existência de um padrão a ser seguido pela protagonista, um papel que obrigatoriamente pertence às mulheres e que por elas deve ser desempenhado. Esse padrão/papel é, para a protagonista, repulsivo, revoltante, desagradável, irritante e sufocante. "Não espanta que as crianças [que supostamente antes ali veveram] o odiassem! Eu mesma o odiaria se tivesse de viver muito tempo neste quarto" (GILMAN, 2017, p. 17-18).

O aprisionamento da personagem nesse quarto, o qual lembra uma sala de aula, nos leva a pensar na educação a que as mulheres foram submetidas por muitos anos. A partir da leitura da obra de Kate Millett (1970) fica podemos relacionar a ideia de que o objetivo da educação da mulher era torná-la sensata e ensinar-lhe a ser de acordo com o papel de mulher importo pela sociedade, não desenvolvendo a sua personalidade. Enquanto o homem podia acessar e conhecer diferentes línguas e ciências, a mulher devia saber apenas o suficiente para participar nos interesses do marido. Segundo o texto de Kate Millett, a educação era

[...] um assunto desagradável para a mentalidade cavalheiresca porque uma instrução decorativa e superficial não só é feminina e estética mas também constitui um complemento dos elevados conhecimentos masculinos. Consciente ou inconscientemente, uma educação séria para a mulher representa uma ameaça para o casamento patriarcal, para os sentimentos domésticos e, enfim, para a supremacia masculina econômica, social e psicológica (MILLETT, 1970, p.101)

O papel de parede amarelo perturba a protagonista, tornando-a obcecada por ele: "Estou começando a me afeiçoar ao quarto, apesar do papel de parede. Talvez por causa dele. Ele ocupa a minha mente. Fico aqui deitada nesta imensa cama que não se mexe - acho que está pregada - e passo horas seguindo o padrão" (GILMAN, 2017, p. 31, grifo da autora), procurando inclusive desvendá-lo:

Em um padrão como esse, à luz do dia, há uma falta de sequência, um desafio às leis, que é uma constante irritação para uma mente normal.

A cor já é medonha o bastante, duvidosa o bastante e enfurecedora o bastante, mas o padrão é torturante. 
Justo quando pensamos tê-lo decifrado, ao avançarmos por sua sequência, ele dá um salto-mortal para trás e nos faz voltar ao princípio. Dá-nos um tapa na cara, lança-nos ao chão e nos pisoteia. É como um pesadelo (GILMAN, 2017, p. 43).

Talvez a dificuldade em entendê-lo se dê porque ela está presa nesse padrão e não o aceita. Apesar disso, a dificuldade de ler o padrão é o que a desafia e possibilita questioná-lo. O estar presa a um quarto com papel de parede amarelo pode ser a indicação de que ela, assim como outras mulheres, está presa a um papel social difícil de entender, que não corresponde à sua(s) subjetividade(s). Os padrões do papel podem ser entendidos como o momento em que ela passa a adentrar um caminho em busca da própria subjetividade, de entender os grilhões sociais que a aprisionam ao papel imposto pela sociedade patriarcal.

Tal ideia fica se realça quando a protagonista passa a ver contornos de uma mulher presa entre 0 papel amarelo e a parede: "posso ver uma espécie de figura disforme, estranha e provocadora, que parece esgueirar-se por trás do desenho tolo e chamativo em primeiro plano" (GILMAN, 2017, p. 26-27). Alguém está preso ao tolo padrão imposto, provavelmente uma mulher. Essa figura precisa esgueirar-se por esse padrão para poder sobreviver, levando-nos a crer que seja a própria figura da protagonista, que finge se adequar para resistir no meio androcêntrico e masculinista.

A protagonista vê uma borda, um contorno, que deduz ser uma mulher, e constitui um novo senso do eu. Um eu que ela não gosta de ver, pois não é quem ela gostaria de ser. Ver nos padrões o papel que a aprisiona lhe causa dor, e provoca autorreflexão:

Há coisas nesse papel que só eu sei, e que ninguém mais virá a saber.

Para além do padrão em primeiro plano, as formas apagadas ficam mais claras a cada dia.

É sempre a mesma forma, só que muito repetida.

Parece uma mulher inclinada para a frente, rastejando em um segundo plano. Não gosto disso nem um pouco. Fico imaginando... Começo a pensar...
Como seria bom se John me levasse embora daqui! (GILMAN, 2017, p. 33).

À medida que a narradora discorre sobre seus pensamentos, afirmando ser uma mulher a figura sob o papel de parede amarelo, inferimos ser este o padrão e este o papel ditador de normas e condutas. Ele coloca a mulher em uma posição de segundo plano, subjugada a ele, um vulto buscando liberdade, ignorado pelos demais:

Por muito tempo fui incapaz de distinguir o que era aquela coisa em segundo plano, aquele subpadrão indistinto, mas agora estou bastante certa de que se trata de uma mulher. Durante o dia ela é discreta, calada. Imagino que seja o padrão que a mantenha tão quieta. É intrigante. Faz com que eu fique quieta durante horas (GILMAN, 2017, p. 45).

O padrão é o que a silencia, principalmente durante o dia, quando os olhos da sociedade se voltam com mais afinco aos comportamentos femininos, a fim de julgá-los. A narradora, ao observar essa mulher, discorre sobre a situação das mulheres como um todo, presas que estão aos papéis sociais, submissas no meio patriarcal. $O$ fato da protagonista não ser nomeada, também pode ser um indício da representação e um coletivo de mulheres subalternas. O padrão as sufoca e não as deixa ser livres. Contudo, à medida que as mulheres se movem, se esgueirando por detrás destes papéis, aos poucos os rasgam, subvertendo-o, abalando-o, podendo esse ser, então, rompido:

O padrão em primeiro plano de fato se move... e não é de surpreender! A mulher ao fundo o balança!

Às vezes tenho a impressão de que são muitas mulheres, às vezes apenas uma, e ela rasteja a toda velocidade, e seu rastejar faz com que tudo balance.

Nos pontos iluminados ela se mantém quieta, e nos pontos sombrios segura as grades e as sacode com força.

E o tempo todo tenta escapar. Mas não há quem consiga atravessar esse padrão - ele é asfixiante; acho que é por isso que tem tantas cabeças.

Assim que elas conseguem atravessar, o padrão as estrangula e as vira de cabeça para baixo, e as faz com que 
seus olhos fiquem brancos! (GILMAN, 2017, p. 56, grifo da autora).

No final do excerto, a narradora diz que o padrão estrangula aquelas que tentam atravessá-lo. Tal imagem nos remete à atitude de John com sua esposa. Ao que parece, ela queria ocupar um lugar, ter sua liberdade de expressão e escrever suas experiências e fantasias, não ser apenas dona de casa e esposa, como sua cunhada. Isso pode não ter agradado John e não ser bem visto pela sociedade, levando-o a afirmar que ela era uma pessoa doente dos nervos. Como não sabemos os motivos pelos quais John diagnosticou nela depressão, beirando à histeria, e como nos foi contado, por meio da voz da protagonista, que ela escrevia mais antes de viver na casa de campo, podemos entender que o adoecimento e "enlouquecimento" dela, determinado por John, é o estrangulamento do padrão àquela que estava buscando se libertar do papel. John sufoca sua esposa a fim de mantê-la sob seu domínio, dentro de uma norma de comportamento feminino, determinado pela sociedade. Friedan ao ver o estado das mulheres que tentam se adaptar ao papel de donas de casa, reflete que

o organismo humano tem o impulso inato para crescer, expandir-se e buscar sua plenitude, não é para admirar que o corpo e a mente de mulheres sadias comecem a revoltar-se quando tentam adaptar-se a um papel que não permite o seu desenvolvimento. Os sintomas que intrigam médicos e analistas são um aviso de que elas não podem destruir sua existência, fugir sem luta à própria evolução (FRIEDAN, 1971, p. 251).

O papel de parede amarelo é como um espelho. A protagonista antecipa a sua imagem, olha através do espelho e vê uma imagem fundida que, aos poucos reconhece como sendo a sua. Ela se vê de fora da sua subjetividade, e vê outras possibilidades para si mesma. Entretanto, ela está presa neste papel e precisa libertar-se para ser e viver essas possibilidades:

Acho que essa mulher sai durante o dia! E em segredo lhes digo por que - eu a vi!
Posso vê-la de cada janela deste quarto!

Sei que é a mesma mulher, porque está sempre rastejando, e a maior parte das mulheres não rasteja durante o dia.

Posso vê-la na longa alameda sombreada, rastejando para cima e para baixo. Posso vê-la sob as vinhas, rastejando por todo o jardim.

Posso vê-la na longa estrada sob as árvores, e quando passa uma carruagem ela se esconde sob as amoreiras.

Não a culpo nem um pouco. Deve ser muito humilhante ser flagrada rastejando à luz do dia!

Sempre tranco a porta quando rastejo durante o dia. Não posso rastejar durante a noite, pois sei que John imediatamente suspeitaria de alguma coisa (GILMAN, 2017, p. 58).

A mulher atrás do papel de parede deixa de ser apenas uma mulher qualquer e passa a ser a própria protagonista. Isso marca o processo de identificação do aprisionamento psíquico e social sofrido por ela. A protagonista age e rasga o padrão, desfaz o papel para libertar a mulher que é:

Tão logo despontou a lua e a pobre mulher começou a rastejar e sacudir o padrão, levantei e corri para ajudá-la. Eu puxava e ela sacudia, eu sacudia e ela puxava, e antes que fosse manhã tínhamos arrancado metros de papel. [...]

E então, quando veio o sol e o medonho padrão começou a rir de mim, decidi que acabaria com ele hoje mesmo! (GILMAN, 2017, p. 64).

Nesse momento, a governanta Jennie vê o papel rasgado pela protagonista e revela que "não se importaria de ter feito ela mesma, e que eu não deveria me cansar" (GILMAN, 2017, p. 64). Através dessa fala percebemos como Jennie, mesmo estando de certa forma conformada com o papel social que lhe foi dado, de alguma forma percebe sua condição de submissão, mas que por comodidade ou por não saber como agir não o rasga. Apesar dela ter esse fio de consciência, Jennie colabora para a manutenção do papel, pois, ao invés de ajudar a protagonista, tenta tirá-la do quarto, interromper o processo, o que reforça a ideia de falta de genealogia entre as mulheres.

A narradora sabe das consequências possíveis em função de seu ato de liberdade. Ela não 
quer mais estar presa ao papel, ter de fingir, de se esconder:

Sei muito bem que um ato como esse é impróprio e poderia ser mal interpretado.

Não quero sequer olhar pelas janelas há tantas mulheres rastejando, e elas rastejam tão depressa!

Fico imaginando: e se todas saírem do papel de parede como eu saí?

Mas agora estou bem atada à minha corda bem escondida - não serei eu a parar na estrada lá embaixo!

Acho que vou ter que voltar para trás do padrão quando vier a noite, e isso é difícil!

É tão agradável estar neste grande quarto e rastejar a meu bel-prazer! (GILMAN, 2017, p. 67).

Essa passagem também nos leva a pensar em um convite à reflexão acerca do que pode acontecer caso todas as mulheres se libertassem do(s) papel(éis) que as aprisionam. Como os padrões poderiam ser rompidos se todas se unissem, ajudassem umas às outras e lutassem por seus direitos. O conto pode ser lido, assim, como uma espécie de alegoria ou de "manifesto feminista" que termina com um grito de liberdade que faz ruir o patriarcado:

Ainda rastejando, olhei para ele [John] por cima do ombro.

"Finalmente consegui saí", respondi, "apesar de você e de Jane! E arranquei a maior parte do papel, então você não vai poder me colocar de volta!"

Ora, que razão teria aquele homem para desmaiar? Mas o fato é que desmaiou, e bem ao lado da parede, no meio do meu caminho, de modo que tive que rastejar por cima dele todas as vezes! (GILMAN, 2017, p. 69).

Outra observação referente a esse excerto é o nome Jane. De acordo com a nota de número 19 do tradutor (p. 109-110), como não há menção de nenhuma Jane, ao longo da história, há a possibilidade de ser apenas um erro de impressão ou digitação do nome Jennie, governanta da casa onde a protagonista está residindo. Contudo, surgiu também a especulação de que a autora, ao mudar o nome, estivesse referindose à própria narradora e sua percepção de ter escapado do marido e dela mesma (Jane). Como se a Jane fosse o eu dela que a mantinha sob a condição de prisioneira ao papel social imposto pelo patriarcado. Desse modo, ela estaria livre do si definido pela sociedade e pelo casamento. Há também a ideia de que Jane seja o nome de registro da governanta Jennie, pois esse, no século XIX, era a alcunha para o nome Jane. Apesar das teorias acerca desse nome, é importante destacar que, apesar das tentativas e meios para conter a protagonista de acordo com o desejado pela sociedade, ela consegue romper o papel, libertando-se.

\section{Considerações finais}

O conto de Charlotte Gilman, por meio da história da protagonista, convida-nos a refletir acerca dos aprisionamentos aos quais as mulheres estão submetidas. Os papéis sociais destinados às mulheres as sufocam e as reprimem de tal modo que, muitas vezes, nem elas percebem as suas próprias condições. A casa, e principalmente o quarto, representam a prisão do casamento para a protagonista, porquanto o matrimônio é um confinamento que a impede de exercer sua subjetividade. Ela vê na escrita a possibilidade de escapar da política social, do papel de mulher e, posteriormente, de doente. Ao não conseguir espaço para si através desse recurso, a protagonista lê o papel e o interpreta, buscando meios de decifrá-lo e, então, transgredi-lo. Sair do papel é um ato resistente de desconstrução, libertação, pelo qual se cobra um preço significativo. Entretanto, esse ato de coragem faz-se necessário para surpassar os papéis (restritos, hierarquizados) designados pela sociedade.

\section{Referências}

A BÍBLIA. Tradução de João Ferreira Almeida. Rio de Janeiro: King Cross Publicações, 2008. Velho Testamento e Novo Testamento.

GILMAN, Charlotte Perkins. O papel de parede amarelo. 3. ed. Trad. Diogo Henriques. Rio de Janeiro: José Olympio, 2017 [1891].

FRIEDAN, Betty. Mística feminina. Tradução de Áurea B. Weissenberg. Petropolis: Vozes Limitada, 1971. 
IRIGARAY, Luce. Yo, tu, nosotras. Trad. Pepa Linhares. Madrid: Cátedra, 1992.

KRAMER, Heinrich; SPRENGER, James. O martelo das feiticeiras. Tradução de Paulo Fróes, Rose Marie Murano, Carlos Byington. 3. ed. Rio de Janeiro: BestBolso, 2016.

LAQUEUR, Thomas Walter. Inventando o sexo: corpo e gênero dos gregos a Freud. Trad. Vera Whately. Rio de Janeiro: Relume Dumará, 2001.

MILLETT, Kate. Política sexual. Tradução de Alice Sampaio; Gisela da Conceição; Manuela Torres. Lisboa: Publicações Dom Quixote, 1970.

SARAMAGO, José. O Evangelho segundo Jesus Cristo: romance. São Paulo: Companhia das Letras, 2005.

$38,2003$.

PRESTES DE OLIVEIRA, Juliana et al. O papel que aprisiona. Signo, Santa Cruz do Sul, v. 45, n. 84, p. 12-21, dez. 2020. ISSN 1982-2014. Disponível em: <https://online.unisc.br/seer/index.php/signo/article/view/15540>. doi:https://doi.org/10.17058/signo.v45i84.15540. 